\title{
Interleukin-1 Receptor Antagonist and Interleukin-4 Genes Variable Number Tandem Repeats Are Associated with Adiposity in Malaysian Subjects
}

\author{
Yung-Yean Kok, Hing-Huat Ong, and Yee-How Say \\ Department of Biomedical Science, Faculty of Science, Universiti Tunku Abdul Rahman (UTAR), Kampar Campus, \\ Jalan Universiti, Bandar Barat, 31900 Kampar, Perak, Malaysia
}

Correspondence should be addressed to Yee-How Say; sayyh@utar.edu.my

Received 5 August 2016; Accepted 17 January 2017; Published 15 February 2017

Academic Editor: Aron Weller

Copyright (C) 2017 Yung-Yean Kok et al. This is an open access article distributed under the Creative Commons Attribution License, which permits unrestricted use, distribution, and reproduction in any medium, provided the original work is properly cited.

\begin{abstract}
Interleukin-1 receptor antagonist (IL1RA) intron 286 bp repeat and interleukin-4 (IL4) intron 370 bp repeat are variable number tandem repeats (VNTRs) that have been associated with various diseases, but their role in obesity is elusive. The objective of this study was to investigate the association of ILIRA and IL4 VNTRs with obesity and adiposity in 315 Malaysian subjects (128 M/187 F; 23 Malays/251 ethnic Chinese/41 ethnic Indians). The allelic distributions of IL1RA and IL4 were significantly different among ethnicities, and the alleles were associated with total body fat (TBF) classes. Individuals with ILIRA I/II genotype or allele II had greater risk of having higher overall adiposity, relative to those having the I/I genotype or I allele, respectively, even after controlling for ethnicity [Odds Ratio $(\mathrm{OR})$ of I/II genotype $=12.21(\mathrm{CI}=2.54,58.79 ; p=0.002)$; II allele $=5.78(\mathrm{CI}=1.73,19.29 ; p=0.004)$ ] However, IL4 VNTR B2 allele was only significantly associated with overall adiposity status before adjusting for ethnicity [OR = $1.53(\mathrm{CI}=1.04,2.23 ; p=0.03)$ ]. Individuals with IL1RA II allele had significantly higher TBF than those with I allele $(31.79 \pm 2.52$ versus $23.51 \pm 0.40 ; p=0.005)$. Taken together, IL1RA intron 2 VNTR seems to be a genetic marker for overall adiposity status in Malaysian subjects.
\end{abstract}

\section{Introduction}

The prevalence of obesity worldwide is rising at alarming rate and has been described as a global pandemic. Malaysia has one of the highest rates of obesity in Asia-Pacific, where the combined prevalence of overweight and obesity was $43.8 \%$ and $48.6 \%$ among men and women above 20 years, respectively [1]. Obesity is closely associated with chronic and low-grade inflammation in the adipose tissue, signified by a lower level of anti-inflammatory cytokines and higher level of proinflammatory cytokines, which in turn differentially activate adipose-tissue macrophages (ATMs) [2]. Specifically, anti-inflammatory cytokines interleukin- (IL-) 13, IL-4, and IL-10 stimulate the alternatively activated ATMs (M2) in lean persons, while obesity induces a shift to the classically activated ATMs (M1) due to stimulation by proinflammatory cytokines TNF- $\alpha$, IL-1 $\beta$, and IL-6 [3].
Interleukin-1 receptor antagonist (IL-1ra), also known as IL-1RN, is an endogenous competitive inhibitor of proinflammatory IL- $1 \alpha$ and IL-1 $\beta$ [4] and is highly secreted by the white adipose tissue (WAT) [5]. IL-1ra is a proadipogenic factor as IL1RA knockout mice have reduced adipose storage, impaired adipogenesis, and decrease in adipocyte size [6], while its level is increased in the serum of obese patients, correlating with body mass index (BMI) and insulin resistance [7]. The human IL-1ra gene (ILIRA or ILIRN) has a Variable Number Tandem Repeat (VNTR) polymorphism within intron 2 due to variation in the number of copies of an $86 \mathrm{bp}$ sequence. To date, six distinct alleles corresponding to $1,2,3,4,5$, and 6 copies of the repeat sequence have been identified [8]. The 4-repeat (allele I) and 2-repeat (allele II) are most frequently found in the general population, while the other four alleles (alleles III, IV, V, and VI) are rarely observed [9]. This VNTR, particularly homozygosity for allele II, has been 
variably associated with various conditions such as obesity, inflammatory bowel disease, and coronary artery disease [reviewed in [10]] in different ethnic populations worldwide.

IL-4, secreted by activated Th2 lymphocytes, basophils, and mast cells, executes many biological roles such as induction of Th2 differentiation, immunoglobulin class switching, and $B$ cell proliferation [11]. In animal studies, diet-induced obese mice had increased splenic lymphocytes production of IL-4 [12], rats receiving visceral fat removal surgery had decreased serum IL-4 [13], and mice treated with IL-4 had improved insulin sensitivity and glucose tolerance while lipid accumulation in adipose tissues was inhibited [14]. These suggest that IL-4 may participate in the processes of dietinduced obesity and metabolism. Similar to ILIRA, IL4 has a $70 \mathrm{bp}$ VNTR polymorphism within intron 3, and two common alleles are B1 and B2 that have two and three tandem repeats, respectively [15]. There have been several reports on the association between the VNTR B1 allele and inflammatory diseases, such as multiple sclerosis [16], rheumatoid arthritis [17], and systemic lupus erythematosus [18]. With regard to obesity, there are limited studies on this VNTR, where two studies showed no association $[19,20]$.

Since the association of ILIRA and IL4 VNTRs with obesity and its related parameters is still elusive especially in Asians, the objectives of this study are therefore to investigate the distribution of ILIRA and IL4 VNTRs genotypes and alleles and to determine whether they are associated with overall obesity (as measured by BMI), central adiposity (as measured by waist circumference, WC), and overall adiposity (as measured by total body fat, TBF) in Malaysian subjects.

\section{Materials and Methods}

2.1. Subjects. Questionnaire and sample collection were carried out using convenience sampling method among unrelated and nonoverlapping 315 subjects comprising of three cohorts (128 or $40.63 \%$ males and 187 or $59.37 \%$ females): (1) 69 Universiti Tunku Abdul Rahman (UTAR), Setapak Campus students and residents of Setapak and Petaling Jaya were recruited from October 2009 to February 2010 [32 males and 37 females; 23 Malays, 40 Chinese, and 6 Indians; mean age 28.49 years]; (2) 20 UTAR Perak Campus students were recruited from October 2011 to January 2012 [9 males and 11 females; all Chinese; mean age 19.90 years]; (3) UTAR Perak Campus students were recruited from January 2013 to May 2013 [ 87 males and 139 females; 192 Chinese and 34 Indians; mean age 21.30 years]. The ethnicities of the subjects were self-identified. All subjects were pooled together for data analysis. This study has received ethical approvals from the UTAR Scientific and Ethical Review Committee (SERC). All subjects signed informed consent forms, and the study was conducted in accordance with the Declaration of Helsinki (amended in Brazil, 2013).

2.2. Questionnaire and Anthropometric Measurements. Clinical and anthropometric measurements, namely, systolic blood pressure (SBP), diastolic blood pressure (DBP), pulse rate, waist circumference (WC), hip circumference (HC), waist-to-hip ratio (WHR), weight, height, body mass index (BMI), and total body fat (TBF), were measured as described in our previous studies $[21,22]$. The cut-off points for obesity, overall adiposity (TBF), and central adiposity (WHR) were $\geq$ $25 \mathrm{~kg} / \mathrm{m}^{2}$ [23], 20\% (males) or 30\% (females) [24], and 0.90 (males) or 0.85 (females) [25], respectively.

2.3. DNA Extraction and Genotyping. Participants were asked to rinse their vigorously with $5 \mathrm{~mL}$ of $3 \%$ sucrose solution for $1 \mathrm{~min}$ and the mouthwash samples were preserved in $3 \mathrm{~mL}$ TNE buffer [17 mM Tris/HCl (pH 8.0), $50 \mathrm{mM} \mathrm{NaCl}$, and $7 \mathrm{mM}$ EDTA]. DNA extraction protocol was then conducted following the protocol as outlined previously [26]. The ILIRA and IL4 VNTRs were genotyped by Polymerase Chain Reaction using the primers, reagents, and conditions adopted from [27] or [20], respectively, with minor modifications. PCR was performed in a $20 \mu \mathrm{L}$ total reaction mixture containing $1 x$ PCR buffer $\left(\mathrm{NH}_{4}\right)_{2} \mathrm{SO}_{4}$ without $\mathrm{MgCl}_{2}$ (PhileKorea, Korea), $1.5 \mathrm{mM} \mathrm{MgCl} 2,0.2 \mathrm{mM}$ dNTPs (PhileKorea, Korea), $0.5 \mu \mathrm{M}$ of forward primer, $0.5 \mu \mathrm{M}$ of reverse primer, $100 \mathrm{ng}$ of DNA template, $0.5 \mathrm{U}$ of Taq polymerase (PhileKorea, Korea), and an appropriate volume of sterile deionized water to top up. The PCR amplification protocol was carried out using the $\mathrm{T}_{100}{ }^{\mathrm{TM}}$ Thermal Cycler PCR machine (Bio-Rad, CA, USA) which began with initial denaturation at $95^{\circ} \mathrm{C}$ for $5 \mathrm{~min}$, followed by 30 cycles of denaturation at $94^{\circ} \mathrm{C}$ for $30 \mathrm{sec}$, annealing at $60^{\circ} \mathrm{C}$ for $30 \mathrm{sec}$ (for IL1RA) or $66^{\circ} \mathrm{C}$ for $45 \mathrm{sec}$ (for IL4), extension at $72^{\circ} \mathrm{C}$ for $30 \mathrm{sec}$ (for IL1RA) or $1 \mathrm{~min}$ (for IL4), and final extension at $72^{\circ} \mathrm{C}$ for $10 \mathrm{~min}$. PCR products were electrophoresed on either 1.5\% (for IL1RA) or 3\% (for IL4) agarose gel, then stained with ethidium bromide, and visualized under UV light after electrophoresis. The sizes of the bands for IL1RA alleles were I: $410 \mathrm{bp}$; II: $240 \mathrm{bp}$; IL4 alleles were B2: $253 \mathrm{bp}$; B1: $183 \mathrm{bp}$ (Figure 1). Three genotypes from each VNTR were verified by DNA sequencing of PCR products (First BASE Laboratories Sdn. Bhd., Malaysia).

2.4. Statistical Analysis. Statistical analysis was carried out using the IBM SPSS Statistics software version 16.0 (IBM, NY, USA). Allelic frequencies were estimated by gene counting and the distribution of genotypes was tested for HardyWeinberg equilibrium using the Chi-square $\left(\chi^{2}\right)$ test. Data for continuous variables were presented as adjusted means \pm standard error of the mean (SEM) and as frequency for categorical variables. The normality of distributions of continuous variables was tested with the Kolmogorov-Smirnov test and variables that were not distributed normally were logtransformed prior to statistical analysis. Genotype and allele frequencies of the polymorphism were assessed for association with demographic and anthropometric classes using Pearson's $\chi^{2}$ test or Fischer's exact test. Logistic regression analysis (enter method) was performed for overall adiposity status with adjustment for covariate ethnicity. Analysis of covariance (ANCOVA) using the univariate General Linear Model with adjustment for covariate ethnicity was performed for anthropometric measurements and blood pressures. ANCOVA was also performed based on BMI status in 


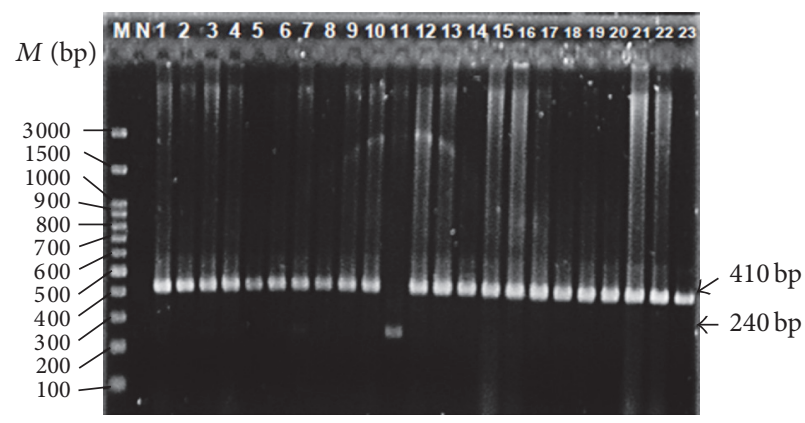

(a)

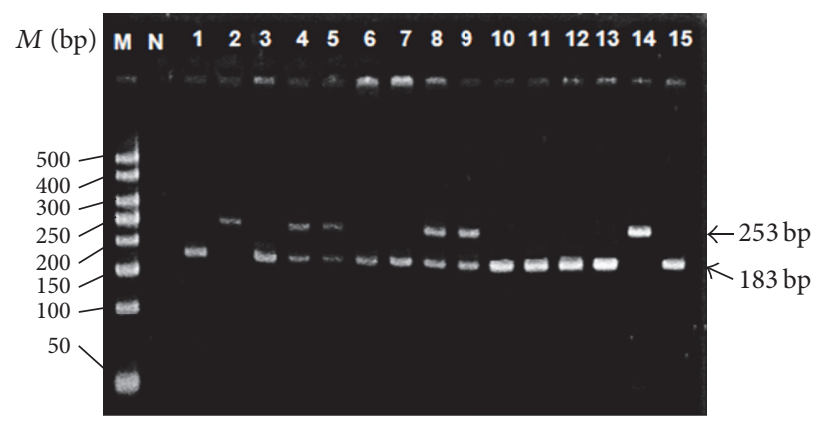

(b)

FIGURE 1: Images of PCR products of (a) IL1RA and (b) IL4 VNTR in 1.5\% or 3.0\% agarose gel, respectively. Lane M: 100 bp or 50 bp DNA ladder (Thermo Fischer Scientific, MA, USA). Lane N: Negative Control. Lanes A1-6: 410/410 bp (I/I). Lane A7: 410/240 bp (I/II). Lane A11: 240/240 bp (II/II). Lanes B1 and 3: 183/183 bp (B1/B1). Lanes B2 and 14: 253/253 bp (B2/B2). Lanes B4 and 5: 253/183 bp (B1/B2).

TABLE 1: Demographic and anthropometric characteristics of the subjects according to gender.

\begin{tabular}{|c|c|c|}
\hline Variables & Male $(n=128)$ & Female $(n=187)$ \\
\hline \multicolumn{3}{|l|}{ Ethnicity } \\
\hline Malay & $11(8.6)$ & $12(6.4)$ \\
\hline Chinese & $104(81.2)$ & $147(78.6)$ \\
\hline Indian & $13(10.2)$ & $28(15.0)$ \\
\hline$\chi^{2} ; p$ & \multicolumn{2}{|c|}{$1.91 ; 0.38$} \\
\hline \multicolumn{3}{|l|}{ BMI class } \\
\hline Nonobese & $103(80.5)$ & $158(84.5)$ \\
\hline Obese & $25(19.5)$ & $29(15.5)$ \\
\hline$\chi^{2} ; p$ & \multicolumn{2}{|c|}{$0.87 ; 0.35$} \\
\hline \multicolumn{3}{|l|}{ WC class } \\
\hline Normal & $104(81.2)$ & $147(78.6)$ \\
\hline High & $24(18.8)$ & $40(21.4)$ \\
\hline$\chi^{2} ; p$ & \multicolumn{2}{|c|}{$0.33 ; 0.57$} \\
\hline \multicolumn{3}{|l|}{ TBF class } \\
\hline Normal & $84(65.6)$ & $137(73.3)$ \\
\hline High & $44(34.4)$ & $50(26.7)$ \\
\hline$\chi^{2} ; p$ & \multicolumn{2}{|c|}{$2.12 ; 0.15$} \\
\hline
\end{tabular}

Parentheses indicate percentage (\%) within the same gender.

stratified analysis. A $p$ value of less than 0.05 was considered as statistically significant.

\section{Results}

The demographic and anthropometric characteristics of the 315 subjects are as shown in Table 1. There was no significant association between gender and the demographic and anthropometric classes.

Table 2 shows the genotype and allele distribution of ILIRA and IL4 VNTRs, which did not deviate from the Hardy-Weinberg equilibrium and are categorized under different demographic and anthropometric classes. The overall minor allele frequencies (MAFs) of ILIRA and IL4 were 0.02 and 0.25 , respectively. The allelic distribution of ILIRA was significantly different between Chinese and Indians and for $I L 4$, it was significantly different between all ethnicities (Table 2). IL1RA and IL4 allele distributions were also significantly associated with TBF class, but not other demographic and anthropometric classes. Genotype distribution of IL4 was also not significantly associated with gender, ethnicity, BMI, $\mathrm{WC}$, and TBF classes.

Since TBF class was significantly associated with both ILIRA and IL4 VNTRs, logistic regression analysis was carried out to study the association of ILIRA and IL4 VNTRs with overall adiposity (TBF) status (Table 3 ). As TBF was significantly different between ethnicities (data not shown), ethnicity was considered as a covariate. The ILIRA VNTR genotype and allele were significantly associated with overall adiposity before and after adjusting for ethnicity. Particularly, subjects with heterozygous I/II genotype had 14.45 times higher risk to have high adiposity compared with subjects with homozygous I/I genotype, while those with allele II had 6.81 times higher risk to have high adiposity compared with subjects with allele I. After controlling for ethnicity, the association of ILIRA genotype and allele with adiposity status remained significant with I/II subjects having 12.21 times higher risk compared with I/I subjects and II subjects having 5.78 times higher risk compared with I subjects (Table 3). However, IL4 VNTR B2 allele was only significantly associated with overall adiposity status before adjusting for ethnicity $[\mathrm{OR}=1.53(\mathrm{CI}=1.04,2.23 ; p=0.03)]$, and this association was abolished after controlling for ethnicity [OR $=1.13(\mathrm{CI}=0.74,1.74 ; p=0.57)]($ Table 3$)$.

Indeed, covariate analysis of variance after controlling for ethnicity also showed similar result, where subjects carrying IL1RA II allele had $8.28 \%$ significantly higher TBF than the those with I allele (Table 4). However, stratified analysis based on BMI status showed that this was only true among nonobese subjects, but not obese subjects (data not shown). All other anthropometric measurements and blood pressures were not significantly different between ILIRA and IL4 VNTR alleles.

\section{Discussion}

In this study, as expected, only allele I and allele II of ILIRA VNTR can be found. The other alleles are too rare to be 


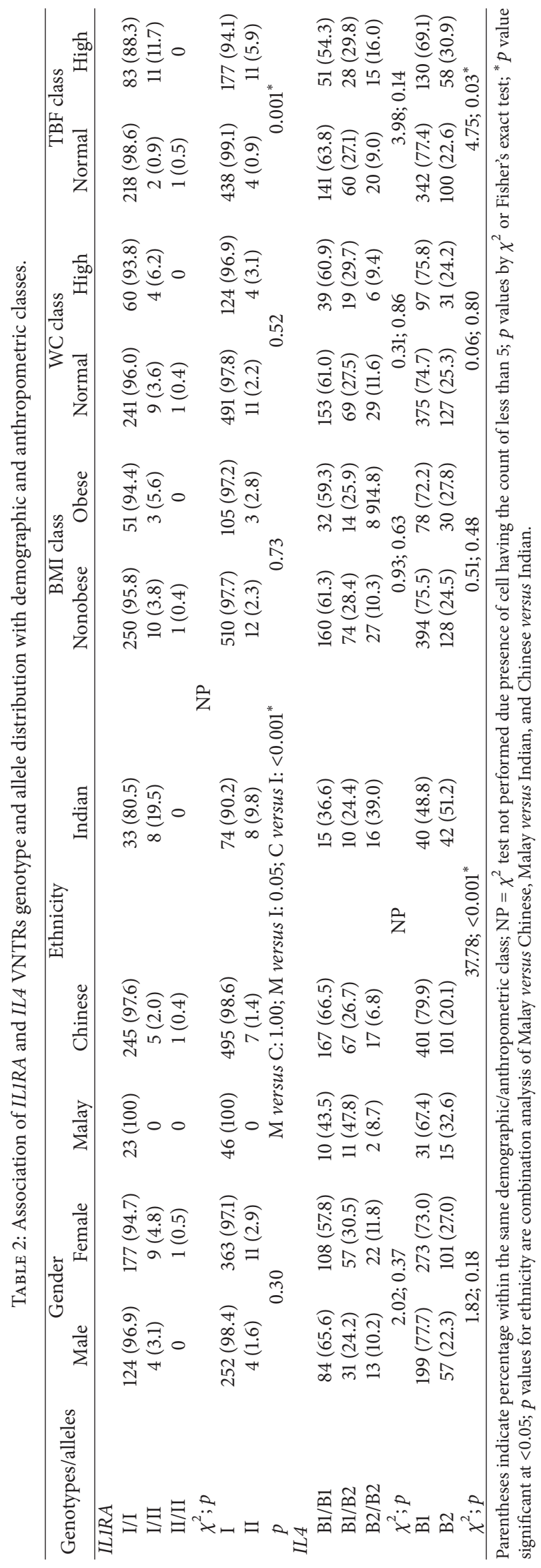


TABLE 3: Logistic regression analysis for the association of IL1RA and IL4 VNTR with overall adiposity status.

\begin{tabular}{|c|c|c|c|c|}
\hline \multirow{2}{*}{ Genotype/allele } & \multicolumn{2}{|c|}{ Unadjusted } & \multicolumn{2}{|c|}{ Adjusted $^{\S}$} \\
\hline & Odds ratio $(95 \% \mathrm{CI})$ & $p$ & Odds ratio (95\% CI) & $p$ \\
\hline \multicolumn{5}{|l|}{$\operatorname{ILIRA}(n ; \%)$} \\
\hline I/I (301; 95.6) & 1.00 & & 1.00 & \\
\hline I/II $(13 ; 4.1)$ & $14.45(3.14,66.56)$ & $0.001^{*}$ & $12.21(2.54,58.79)$ & $0.002^{*}$ \\
\hline II/II $(1 ; 0.3)$ & NP & 1.00 & NP & 1.00 \\
\hline I $(615 ; 97.6)$ & 1.00 & & 1.00 & \\
\hline II $(15 ; 2.4)$ & $6.81(2.14,21.66)$ & $0.001^{*}$ & $5.78(1.73,19.29)$ & $0.004^{*}$ \\
\hline \multicolumn{5}{|l|}{ IL4 ( $n ; \%)$} \\
\hline B1/B1 $(192 ; 61.0)$ & 1.00 & & 1.00 & \\
\hline B1/B2 (88; 27.9) & $2.07(0.99,4.36)$ & 0.05 & $1.32(0.57,3.06)$ & 0.53 \\
\hline B2/B2 (35; 11.1) & $1.29(0.74,2.24)$ & 0.37 & $1.01(0.55,1.85)$ & 0.97 \\
\hline B1 $(472 ; 74.9)$ & 1.00 & & 1.00 & \\
\hline B2 $(158 ; 25.1)$ & $1.53(1.04,2.23)$ & $0.03^{*}$ & $1.13(0.74,1.74)$ & 0.57 \\
\hline
\end{tabular}

${ }^{\S}$ Adjusted for covariate ethnicity; values are by logistic regression enter method; ${ }^{*} p$ value significant at $<0.05$.

TABLE 4: Adjusted means of overall population's anthropometric measurements and blood pressures for different IL1RA and IL4 VNTR alleles.

\begin{tabular}{|c|c|c|c|c|}
\hline \multirow{2}{*}{ Variables } & \multicolumn{2}{|c|}{$I L 1 R A$} & \multicolumn{2}{|c|}{ IL4 } \\
\hline & I & II & B1 & B2 \\
\hline WC & $77.16 \pm 0.48$ & $81.98 \pm 3.06$ & $79.59 \pm 1.59$ & $79.55 \pm 2.64$ \\
\hline$p$ & \multicolumn{2}{|c|}{0.09} & \multicolumn{2}{|c|}{0.99} \\
\hline BMI & $21.83 \pm 0.18$ & $23.26 \pm 1.12$ & $22.54 \pm 0.58$ & $22.55 \pm 0.97$ \\
\hline$p$ & \multicolumn{2}{|c|}{0.14} & \multicolumn{2}{|c|}{0.95} \\
\hline $\mathrm{TBF}$ & $23.51 \pm 0.40$ & $31.79 \pm 2.52$ & $26.09 \pm 1.31$ & $29.21 \pm 2.18$ \\
\hline$p$ & \multicolumn{2}{|c|}{$0.005^{*}$} & \multicolumn{2}{|c|}{0.34} \\
\hline SBP & $113.26 \pm 0.68$ & $108.95 \pm 4.32$ & $114.65 \pm 2.24$ & $107.56 \pm 3.73$ \\
\hline$p$ & \multicolumn{2}{|c|}{0.19} & \multicolumn{2}{|c|}{0.06} \\
\hline DBP & $68.81 \pm 0.41$ & $68.66 \pm 2.60$ & $68.22 \pm 1.35$ & $69.25 \pm 2.25$ \\
\hline$p$ & \multicolumn{2}{|c|}{0.68} & \multicolumn{2}{|c|}{0.37} \\
\hline
\end{tabular}

WHR: waist-to-hip ratio; BMI: body mass index; TBF: total body fat; SBP: systolic blood pressure; DBP: diastolic blood pressure; all values were log-transformed before analysis by univariate analysis of variance (General Linear Model), adjusted for covariate ethnicity; values are presented as adjusted mean \pm SEM (estimated marginal means \pm standard error of the mean); ${ }^{*} p$ valuesignificant at $<0.05$.

found in most of the populations [27]. The IL1RA VNTR is considered a rare genetic polymorphism, as the MAF was 0.02 (less than 0.05 ). There is significant proof to show that ILIRA VNTR is highly influenced by ethnicity [reviewed in [27]]. A study in 19 Chinese populations found out that allele I had higher frequency than allele II, which were 0.913 and 0.064 , respectively, indicating that the prevalence of allele I in China was significantly higher, and the prevalence of allele II was significantly lower than American and European Caucasian populations [28]. Similarly in African and AfricanAmerican people, the frequency of allele II homozygotes is considerably lower than that in the Caucasian population [29]. Alike with $I L 1 R A$, the allele and genotype frequencies for IL4 VNTR in our population are strikingly different from those of the Caucasian population [17, 30-32], with our MAF of 0.25 being more similar to the Japanese population $(\mathrm{MAF}=$ 0.33 ) [33] and a previous Malaysian study (MAF $=0.37)$ [34].

IL-1ra serum level is increased in human obesity and is under strong genetic control [5], partly by the IL1RA VNTR polymorphism. Indeed, IL1RA allele II has a clear influence on IL-1ra circulating levels since, in normal human subjects, its carrier individuals had higher levels than the noncarrier individuals (745 ng/mL versus $627 \mathrm{pg} / \mathrm{mL}$ ) [35]. With regard to obesity, two previous Asian studies with relatively small sample sizes found no significant association of IL1RA VNTR with BMI in Koreans $(N=261)[36]$ and North Indians $(N=$ 103) [37]. Similarly, our study found no association with BMI value or overall obesity status, but IL1RA VNTR was associated with both TBF value and overall adiposity status. In stratified analysis, $\mathrm{TBF}$ value was found to be higher in subjects carrying IL1RA II allele than those with I allele, only among nonobese subjects. This could be attributed to the low BMI and high TBF paradox among Malays/Chinese/Indians, as shown previously [38]. The ILIRA VNTR may have functional significance as the repeated sequence contains possible binding sites for transcription factors [9]. A review by Witkin et al. 2002 [10] summarized that individuals homozygous for allele II have more prolonged and severe proinflammatory immune response than persons with other ILIRA genotypes, which might be beneficial when combating 
infectious agents [39] or neoplasms [40], but is detrimental for those with chronic inflammatory conditions [41] or those who are pregnant [42].

The IL4 VNTR which is located in IL4 intron 3 could be a functional polymorphism as it could affect mRNA splicing, leading to different splice variants [43]. Indeed, the $\mathrm{B} 2$ allele has been associated with reduced amount of peripheral Th cells which produce IL-4 [33]. Our study showed that this VNTR was associated with overall adiposity status (TBF class), but not with TBF value after adjustment for ethnicity. However, consistent with two previous studies which showed no association of this VNTR with obesity status in North Indian [19] and Turkish [20] populations, we found no association with both BMI value and overall obesity status. The role of IL-4 in modulating adipogenesis has been established by previous studies. Tsao et al. (2014) [44] showed IL-4 inhibited adipogenesis via STAT6 pathway or by influencing the cell proliferation at the mitotic clonal expansion phase. IL-4 also enhances lipolysis via the PKA pathway in mature adipocytes [44]. Other study carried out by Rao et al. (2014) [45] revealed that IL-4 signaling activates macrophages in WAT, leading to the production of nervous system molecules required for converting WAT to beige fat. Taken together, the direct functional significance of ILIRA and IL4 VNTRs particularly on affected tissues in obesity (like adipose tissue) and other metabolic disease (like type 2 diabetes mellitus) warrants further investigation.

Limitations of the present study include the small sample size of Malay and Indian subjects and the lack of other indigenous ethnic groups especially from East Malaysia (Sabah and Sarawak); hence the results from this study may not be fully representative of the general Malaysian population. Other common genetic variants like the $I L-1 \beta$ promoter region and exon-5 and IL4 -590 T/C single nucleotide polymorphisms, which were not screened in this study, could have association with obesity and its related parameters. The direct phenotypegenotype correlation could also be determined by measuring the serum levels of IL-1ra and IL-4 using ELISA in the future.

Obesity results in a proinflammatory state which involves the release of cytokines and adipokines by adipose tissue. Indeed, the main finding of this study shows that VNTR genetic polymorphisms in two genes, IL1RA and IL4, encoding for anti-inflammatory cytokines IL-1ra and IL4 , respectively, are associated with overall adiposity status (TBF) in Malaysian subjects, before controlling for ethnicity. ILIRA VNTR shows a more prominent effect, as TBF was significantly higher in those with ILIRA II allele compared with I allele, even after controlling for ethnicity. Individuals with IL4 VNTR B2 allele had higher risk of having higher adiposity, but the association was abolished after controlling for ethnicity. Taken together, ILIRA intron 2 VNTR seems to be a genetic marker for overall adiposity status in Malaysian subjects.

\section{Disclosure}

Preliminary results of this study were presented as a poster presentation at the 6th Malaysian Symposium of Biomedical Science, May 16-17, 2015.

\section{Competing Interests}

The authors declare no conflict of interests.

\section{Acknowledgments}

This work was supported by grant from the Department of Biomedical Science, UTAR. The authors gratefully acknowledge all the volunteers who have participated in this study.

\section{References}

[1] M. Ng, T. Fleming, M. Robinson et al., "Global, regional, and national prevalence of overweight and obesity in children and adults during 1980-2013: a systematic analysis for the Global Burden of Disease Study 2013," The Lancet, vol. 384, no. 9945, pp. 766-781, 2014.

[2] G. S. Hotamisligil, "Inflammation and metabolic disorders," Nature, vol. 444, no. 7121, pp. 860-867, 2006.

[3] C. J. Shu, C. Benoist, and D. Mathis, "The immune system's involvement in obesity-driven type 2 diabetes," Seminars in Immunology, vol. 24, no. 6, pp. 436-442, 2012.

[4] S. Perrier, F. Darakhshan, and E. Hajduch, "IL-1 receptor antagonist in metabolic diseases: Dr Jekyll or Mr Hyde?" FEBS Letters, vol. 580, no. 27, pp. 6289-6294, 2006.

[5] C. E. Juge-Aubry, E. Somm, V. Giusti et al., "Adipose tissue is a major source of interleukin-1 receptor antagonist: upregulation in obesity and inflammation," Diabetes, vol. 52, no. 5, pp. 11041110, 2003.

[6] E. Somm, E. Henrichot, A. Pernin et al., "Decreased fat mass in interleukin-1 receptor antagonist-deficient mice: impact on adipogenesis, food intake, and energy expenditure," Diabetes, vol. 54, no. 12, pp. 3503-3509, 2005.

[7] C. A. Meier, E. Bobbioni, C. Gabay, F. Assimacopoulos-Jeannet, A. Golay, and J.-M. Dayer, "IL-1 receptor antagonist serum levels are increased in human obesity: a possible link to the resistance to leptin?" Journal of Clinical Endocrinology and Metabolism, vol. 87, no. 3, pp. 1184-1188, 2002.

[8] J. E. Vamvakopoulos, C. J. Taylor, G. J. Morris-Stiff, C. Green, and S. Metcalfe, "The interleukin-1 receptor antagonist gene: a single-copy variant of the intron 2 variable number tandem repeat (VNTR) polymorphism," European Journal of Immunogenetics, vol. 29, no. 4, pp. 337-340, 2002.

[9] J. K. Tarlow, A. I. F. Blakemore, A. Lennard et al., "Polymorphism in human IL-1 receptor antagonist gene intron 2 is caused by variable numbers of an 86-bp tandem repeat," Human Genetics, vol. 91, no. 4, pp. 403-404, 1993.

[10] S. S. Witkin, S. Gerber, and W. J. Ledger, "Influence of interleukin-1 receptor antagonist gene polymorphism on disease," Clinical Infectious Diseases, vol. 34, no. 2, pp. 204-209, 2002.

[11] K. Nelms, A. D. Keegan, J. Zamorano, J. J. Ryan, and W. E. Paul, "The IL-4 receptor: signaling mechanisms and biologic functions," Annual Review of Immunology, vol. 17, pp. 701-738, 1999.

[12] N. Mito, T. Hosoda, C. Kato, and K. Sato, "Change of cytokine balance in diet-induced obese mice," Metabolism: Clinical and Experimental, vol. 49, no. 10, pp. 1295-1300, 2000.

[13] S. E. Borst, C. F. Conover, and G. J. Bagby, "Association of resistin with visceral fat and muscle insulin resistance," Cytokine, vol. 32, no. 1, pp. 39-44, 2005. 
[14] Y.-H. Chang, K.-T. Ho, S.-H. Lu, C.-N. Huang, and M.-Y. Shiau, "Regulation of glucose/lipid metabolism and insulin sensitivity by interleukin-4," International Journal of Obesity, vol. 36, no. 7, pp. 993-998, 2012.

[15] R. Mout, R. Willemze, and J. E. Landegent, "Repeat polymorphisms in the interleukin-4 gene (IL4)," Nucleic Acids Research, vol. 19 , no. 13, p. 3763, 1991.

[16] T. Olsson, "Cytokine-producing cells in experimental autoimmune encephalomyelitis and multiple sclerosis," Neurology, vol. 45, pp. S11-S15, 1995.

[17] N. Buchs, T. Silvestri, F. S. di Giovine et al., "IL-4 VNTR gene polymorphism in chronic polyarthritis. The rare allele is associated with protection against destruction," Rheumatology, vol. 39, no. 10, pp. 1126-1131, 2000.

[18] M.-C. Wu, C.-M. Huang, J. J. P. Tsai, H.-Y. Chen, and F.-J. Tsai, "Polymorphisms of the interleukin- 4 gene in Chinese patients with systemic lupus erythematosus in Taiwan," Lupus, vol. 12, no. 1, pp. 21-25, 2003.

[19] R. C. Sobti, N. Maithil, H. Thakur, Y. Sharma, and K. K. Talwar, "VEGF and IL-4 gene variability and its association with the risk of coronary heart disease in north Indian population," Molecular and Cellular Biochemistry, vol. 341, no. 1-2, pp. 139$148,2010$.

[20] A. Tekcan, S. Yigit, A. Rustemoglu, C. Gurel, S. Sahin, and T. Tasliyurt, "The investigation of obesity susceptibility with IL-4 gene intron 3 VNTR and IL-6 gene -597G/A polymorphisms in a turkish population," International Journal of Human Genetics, vol. 13, no. 4, pp. 209-213, 2013.

[21] S.-K. Yiew, L.-Y. Khor, M.-L. Tan et al., "No association between peroxisome proliferator-activated receptor and uncoupling protein gene polymorphisms and obesity in Malaysian university students," Obesity Research and Clinical Practice, vol. 4, no. 4, pp. e325-e331, 2010.

[22] P. M. Chan, S. H. Fan, and Y. H. Say, "No association of Peptide Tyrosine-Tyrosine (PYY) gene R72t variant with obesity in the Kampar Health Clinic Cohort, Malaysia," Malaysian Journal of Nutrition, vol. 17, no. 2, pp. 201-212, 2011.

[23] WHO/IOTF/IASO, The Asia-Pacific Perspective: Redefining Obesity and Its Treatment, World Health Organization, International Obesity Task Force, International Association for the Study of Obesity, Hong Kong, 2000.

[24] Omron, Omron KARADA Scan Body Composition \& Scale (HBF-362), Omron Healthcare, Muko, Japan, 2007.

[25] WHO, Waist Circumference and Waist-hip Ratio: Report of a WHO Expert Consultation, WHO Press, Geneva, Switzerland, 2011.

[26] M. Aidar and S. R. P. Line, "A simple and cost-effective protocol for DNA isolation from buccal epithelial cells," Brazilian Dental Journal, vol. 18, no. 2, pp. 148-152, 2007.

[27] P. K. Manchanda, H. K. Bid, and R. D. Mittal, "Ethnicity greatly influences the interleukin-1 gene cluster(IL-1 $\beta \beta$ promoter, exon-5 and IL-1Ra) polymorphisms: a pilot study of a north Indian population," Asian Pacific journal of cancer prevention: APJCP, vol. 6, no. 4, pp. 541-546, 2005.

[28] J. Jiang, X. Zhang, D. Sun et al., "Study on VNTR polymorphism of gene IL-1RA in 19 Chinese populations," International Journal of Immunogenetics, vol. 37, no. 2, pp. 73-77, 2010.

[29] C. G. Parks, G. S. Cooper, M. A. Dooley et al., "Systemic lupus erythematosus and genetic variation in the interleukin 1 gene cluster: a population based study in the southeastern United States," Annals of the Rheumatic Diseases, vol. 63, no. 1, pp. 9194, 2004.
[30] K. Vandenbroeck, G. Martino, M. G. Marrosu et al., "Occurrence and clinical relevance of an interleukin-4 gene polymorphism in patients with multiple sclerosis," Journal of Neuroimmunology, vol. 76, no. 1-2, pp. 189-192, 1997.

[31] D. Huang, S. Xia, Y. Zhou, R. Pirskanen, L. Liu, and A. K. Lefvert, "No evidence for interleukin-4 gene conferring susceptibility to myasthenia gravis," Journal of Neuroimmunology, vol. 92, no. 1-2, pp. 208-211, 1998.

[32] A. Cantagrel, F. Navaux, P. Loubet-Lescoulié et al., "Interleukin$1 \beta$, interleukin-1 receptor antagonist, interleukin-4, and interleukin-10 gene polymorphisms: relationship to occurrence and severity of rheumatoid arthritis," Arthritis and Rheumatism, vol. 42, no. 6, pp. 1093-1100, 1999.

[33] H. Nakashima, K. Miyake, Y. Inoue et al., "Association between IL-4 genotype and IL-4 production in the Japanese population," Genes and Immunity, vol. 3, pp. 107-109, 2002.

[34] R. Vasudevan, M. N. Norhasniza, and I. Patimah, "Association of variable number of tandem repeats polymorphism in the IL-4 gene with end-stage renal disease in Malaysian patients," Genetics and Molecular Research, vol. 10, no. 2, pp. 943-947, 2011.

[35] M. Hurme and S. Santtila, "IL-1 receptor antagonist (IL-1Ra) plasma levels are co-ordinately regulated by both IL-1Ra and IL-1 $\beta$ genes," European Journal of Immunology, vol. 28, no. 8, pp. 2598-2602, 1998.

[36] J.-Y. Um, H.-M. Kim, S.-W. Mun, Y.-S. Song, and S.-H. Hong, "Interleukin-1 receptor antagonist gene polymorphism and traditional classification in obese women," International Journal of Neuroscience, vol. 116, no. 1, pp. 39-53, 2006.

[37] P. K. Manchanda, H. K. Bid, B. R. Achyut, B. Mittal, N. Srivastava, and R. D. Mittal, "Interleukin-1 receptor antagonist gene polymorphism and obesity: A Pilot Study from North India," Indian Journal of Clinical Biochemistry, vol. 22, no. 1, pp. 61-64, 2007.

[38] M. Deurenberg-Yap, G. Schmidt, W. A. Van Staveren, and P. Deurenberg, "The paradox of low body mass index and high body fat percentage among Chinese, Malays and Indians in Singapore," International Journal of Obesity, vol. 24, no. 8, pp. 1011-1017, 2000.

[39] M. Hurme and M. Helminen, "Resistance to human cytomegalovirus infection may be influenced by genetic polymorphisms of the tumour necrosis factor-alpha and interleukin-1 receptor antagonist genes," Scandinavian Journal of Infectious Diseases, vol. 30, no. 5, pp. 447-449, 1998.

[40] A. Mustea, J. Sehouli, D. Könsgen, D. Stengel, D. Sofroni, and W. Lichtenegger, "Interleukin 1 receptor antagonist (IL1RA) polymorphism in women with cervical cancer," Anticancer Research, vol. 23, no. 2A, pp. 1099-1102, 2003.

[41] O. Mwantembe, M.-C. Gaillard, M. Barkhuizen et al., "Ethnic differences in allelic associations of the interleukin-1 gene cluster in south african patients with inflammatory bowel disease (IBD) and in control individuals," Immunogenetics, vol. 52, no. 3-4, pp. 249-254, 2001.

[42] S. Salimi, M. Mohammadoo-Khorasani, M. Yaghmaei, M. Mokhtari, and M. Moossavi, "Possible association of IL-4 VNTR polymorphism with susceptibility to preeclampsia," BioMed Research International, vol. 2014, Article ID 497031, 5 pages, 2014.

[43] A. Inanir, S. Tural, S. Yigit et al., "Association of IL-4 gene VNTR variant with deep venous thrombosis in Behçet's disease and its effect on ocular involvement," Molecular Vision, vol. 19, pp. 675683, 2013. 
[44] C.-H. Tsao, M.-Y. Shiau, P.-H. Chuang, Y.-H. Chang, and J. Hwang, "Interleukin-4 regulates lipid metabolism by inhibiting adipogenesis and promoting lipolysis," Journal of Lipid Research, vol. 55, pp. 385-397, 2014.

[45] R. R. Rao, J. Z. Long, J. P. White et al., "Meteorin-like is a hormone that regulates immune-adipose interactions to increase beige fat thermogenesis," Cell, vol. 157, no. 6, pp. 12791291, 2014. 


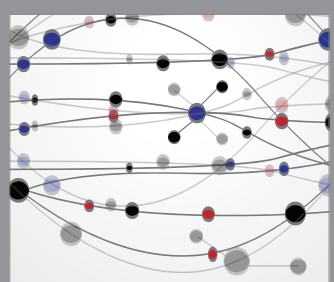

The Scientific World Journal
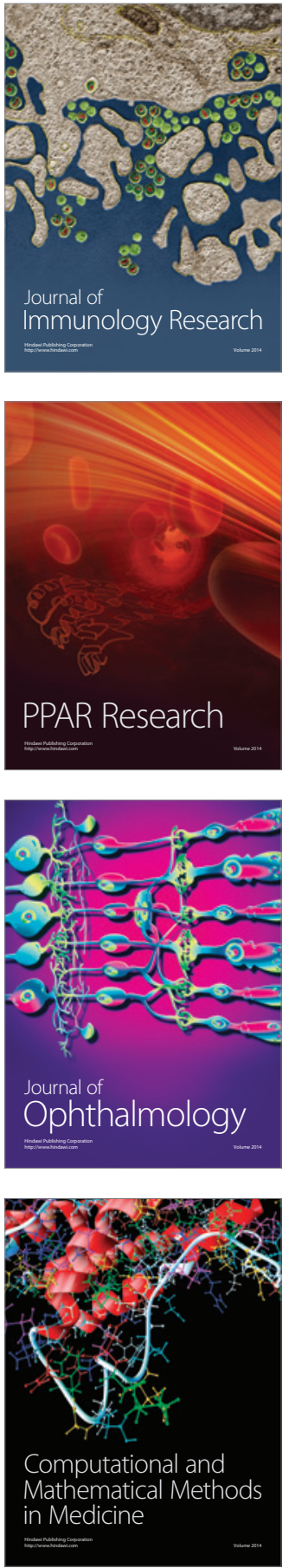

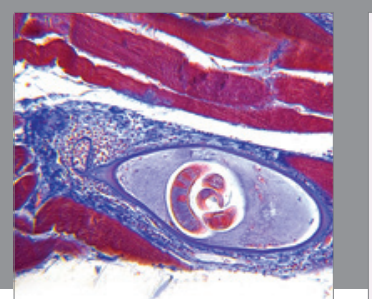

Gastroenterology Research and Practice
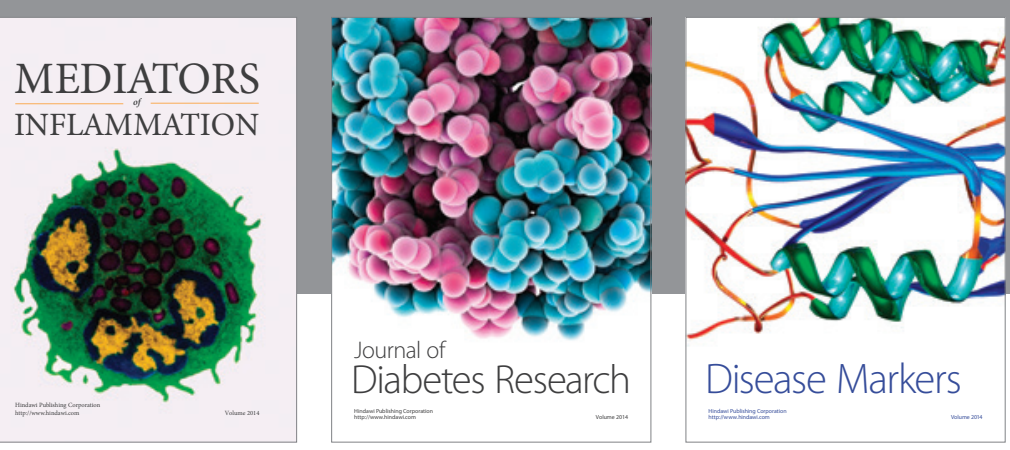

Disease Markers

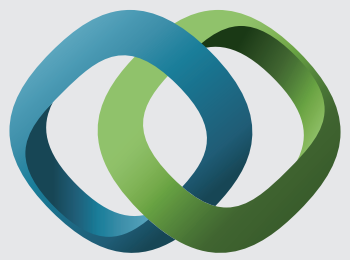

\section{Hindawi}

Submit your manuscripts at

https://www.hindawi.com
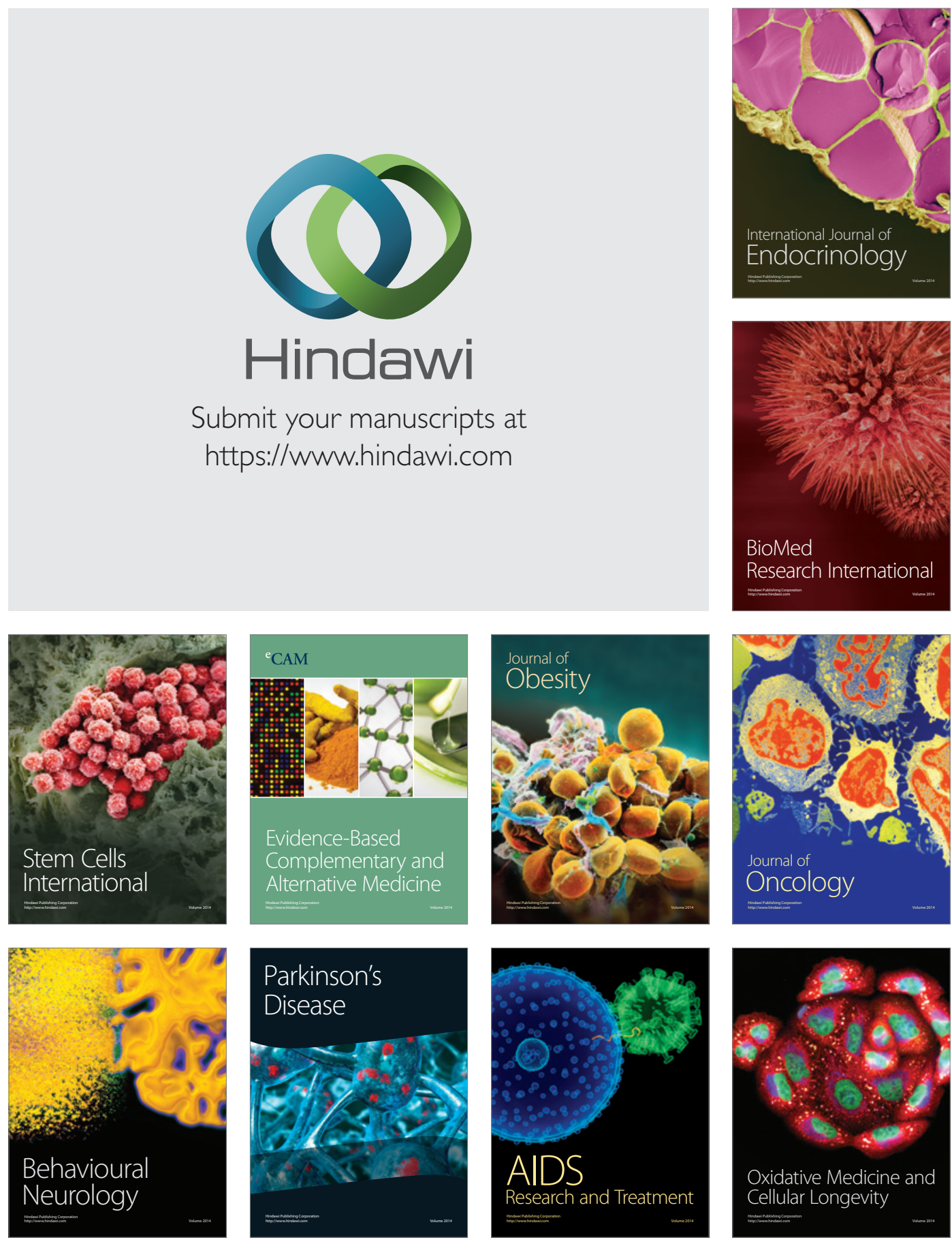